\title{
Is Memory Merely Testimony from One's Former Self?
}

\section{Introduction}

Is memory merely testimony from one's former self? The short answer is, 'No'.1 The longer answer will require some setup. We can start with an example.

Detective Story: After examining his clues, a detective concludes that it was Prof. Plum who committed the murder. When he later speaks to the chief of police, the detective reports this conclusion to the chief without recalling the clues.

Our Detective Story leaves out a number of details. It leaves out whether the detective's clues really do support his conclusion that it was Prof. Plum who committed the murder. It also leaves out whether the chief holds the detective's abilities in high or low regard, and whether he has good reasons supporting whatever attitude he holds. So we cannot say, based solely on the information in the story, whether the detective is justified in the first place in concluding that it was Prof. Plum who committed the murder. Nor can we say whether the chief is justified in taking the detective's word for it that it was Plum. Nevertheless, we can say something about the kinds of factors on which the justification of their beliefs depends.

Consider first the detective. When he initially concludes that it was Prof. Plum who committed the murder, the reasons that persuade him are his clues. So in the absence of other relevant evidence, whether the detective is justified in believing that it was Plum will depend on whether these clues amount to good reasons to believe it was Plum. When he later reports to the chief that it was Plum, it is appealing to say that unless he has changed his mind in the meantime, his reasons still are the clues themselves. Consequently, it is appealing to say that whether he is justified still depends on whether the clues amount to good reasons to believe that it was Plum.

Turn now to the chief of police. His situation is different. For the chief does not know the clues that led the detective to believe it was Plum. It is appealing to say that

For comments, advice, and discussion, I am grateful to Matthew Anisfeld, Yuval Avnur, Paul Boghossian, Justin Clarke-Doane, Jonathan Cottrell, Sinan Dogramaci, Hartry Field, Don Garrett, Peter J. Graham, Alex Guerrero, Pamela Hieronymi, Jonathan Jenkins Ichikawa, Beatrice Longuenesse, Colin Marshall, Tom Nagel, Ram Neta, Jim Pryor, Stephen Schiffer, Declan Smithies, Sharon Street, Nick Treanor, David Velleman, Crispin Wright, three anonymous referees at this journal, and audiences at Duke University, the Northern Institute of Philosophy, Union College, the NYU dissertation seminar, and my Spring 2013 seminar on Intellectual Autonomy and Dependence at Union College. I also wish to thank the University of Edinburgh's Eidyn Centre and the Union College Humanities Faculty Research Fund for their support.

1 Among the theorists who have discussed both the epistemology of memory and testimony, answering 'Yes' has been the dominant trend, exemplified in different ways by Burge (1993 and 1997), Christensen and Kornblith (1997), Lackey (2008), Owens (2000, Chs. 9-11), and Schmitt (2006). Although not all authors who have written on the epistemologies of memory and testimony have taken a stand on the question, I know of no one aside from Malmgren (2006 and forthcoming) who has argued that the epistemologies of memory and testimony differ fundamentally. 
whether the chief is justified in believing that it was Plum does not depend on whether the detective's clues amount to good reasons. Instead, if the chief is to be justified, then he will need his own good reasons to believe it was Plum. Since the chief knows only that the detective says it was Plum, it is appealing to think that whether the chief is justified in believing that it was Plum will depend on the chief's evidence concerning the detective's reliability.

We have considered a pair of prima facie attractive claims, one concerning the epistemic position of the detective, and the other concerning the position of the chief. Concerning the detective, we have said that his justification to believe it was Plum depends on whether the clues are good reasons to believe it was Plum. Concerning the chief, we have said that his justification depends not on whether the detective's clues are good reasons, but instead on the chief's own reasons for trusting the detective. If we accept this pair of claims, then we will say that the justification of the detective's belief and the chief's depend on different kinds of factors.

Later on, I plan to argue for more general versions of these prima facie attractive claims. But before doing so, I want to explain how, taken together, they raise a puzzle. Consider a sequel to our detective story:

Sequel: Years later, the detective has forgotten the conclusion and the clues. He finds his long-lost diary, in which he had once recorded his conclusion. In the diary he finds it written that it was Prof. Plum.

When we consider the Sequel and the original Detective Story side by side, we are faced with a puzzle. For it is very appealing, and I think correct, to compare the detective's new epistemic situation to the chief's. That is, it is appealing to say that testimony from one's former self is epistemically akin to testimony from another person, and that the conditions in which one is justified in believing an item of testimony are the same regardless of whether its source is one's former self or someone else.

At the same time, it also is very appealing, although I will claim ultimately misguided, to compare the detective's new situation to the detective's situation when he reported his conclusion to the chief. That is, it is appealing to say that recalling a prior conclusion from memory is akin to receiving testimony from one's former self, and that the conditions in which one is justified in believing what one seems to remember are analogous to those in which one is justified in believing what one instead reads in one's diary. The theorist who accepts this, and says that memory is like a diary, might say that it should not matter whether your memories are stored internally or are instead recorded externally in a diary, since these can appear to be two closely analogous means of accomplishing the same end. This theorist's rough idea is that memory serves as a means for your present self to gain evidence about what your former self came to believe, just as testimony arguably serves as a means of gaining evidence about what someone else believes. We will be in a better position to clarify this appealing, but in my view misguided, idea later on. For now, we can characterize the view using a rough but suggestive slogan: Memory is like a diary.

The plan is as follows. In Sections 2 and 3, I will consider epistemology of testimony from others and the epistemology of ordinary memory, respectively, and I will try to reinforce the appealing claim that the justification of memory- and testimony-based beliefs depend on different factors. In Section 4, I will consider a misguided attempt to explain why the justification of memory- and testimony-based beliefs depend on different 
factors, which incorrectly treats testimony from one's former self as akin to memory rather than as akin to testimony from others. In Section 5, I will introduce my preferred account, which appeals to a tight connection between the justification of a belief and its rational explanation. As I will explain, the account appeals to an independently plausible but potentially controversial set of claims about how the 'internal' faculty of memory and an 'external' source of information like a diary each contribute to the overall rational explanation of an agent's beliefs. Finally, in Sections 6 and 7, I will consider the epistemic implications of revisionary metaphysical views that deny that memory and testimony differ in the way that I claim, either by extending the mind to include the apparently external source or by contracting the mind to exclude the apparently internal faculty of memory.

\section{Testimony from others}

Suppose that you are in midtown Manhattan searching for the Museum of Modern Art (MoMA). If you ask a stranger where it is, and that stranger tells you that it's on 53rd St, then that is an example of testimony. When the detective reports to the chief that it was Prof. Plum who committed a murder, that too is an example of testimony. In ordinary cases of testimony like these, it is common knowledge that the reliability of a source's testimony depends both on the reliability of the source's beliefs and on her sincerity in stating only what she believes. Because my central aim is to contest the analogy between memory and testimony, I will focus on the ordinary cases, where the analogy with memory is on its strongest grounds. ${ }^{2}$

Here I will explain and defend what I call the naive theory of testimony. I call it that even though I agree with it, because I find that it is the view many philosophers find appealing when they first start thinking about testimony. The naive theory says that when a source of testimony tells you that $\mathrm{p}$, what you learn first is not $\mathrm{p}$ itself but instead merely the fact that that the source says that $\mathrm{p}$. So if you are to be justified in believing that $\mathrm{p}$ on the basis of what you learn first, you must be in a situation where the fact that the source says that $\mathrm{p}$ is a good reason for you to believe that $\mathrm{p}$ is true. The naive theory says something further about what it takes to be in such a situation. It says that it does not depend on 'external' factors, like whether the source is objectively reliable or whether the source actually knows that p. Instead, it depends only on 'internal' factors, like whether you have any reason to doubt that the source is reliable, or whether you have evidence suggesting that the source knows whether p. Since it is common knowledge in ordinary cases that the reliability of a source's testimony depends on both whether his testimony reflects what he sincerely believes and whether his beliefs reliably indicate the truth, I will take it for granted that in these ordinary cases the naive theorist must say that your justification to believe a source's

\footnotetext{
2 In addition to ordinary cases, there are exotic cases which neither obviously qualify nor obviously fail to qualify as cases of testimony. For example, consider Lackey's case of the creationist teacher (2008, 48-53), who in a professional capacity tells her students that humans descended from other hominids even though she does not believe it. Even though the teacher is both insincere and unreliable in her privately held beliefs, Lackey claims that her students can still know what she tells them, and that this knowledge still qualifies as testimonial knowledge. It is not necessary for our purposes to settle these matters. We need only to make some generalizations about the ordinary cases of testimony, without having to decide whether we have succeeded in offering a general theory that applies to all cases.
} 
testimony depends on your justification ${ }^{3}$ to believe that the source is both sincere and reliable. In doing so, I will take the naive theory to say about these ordinary cases that for you a source's testimony serves first as evidence about what that source believes, and that in turn can serve as evidence concerning what is true.

The naive theory is intended to be compatible with a number of familiar views in the literature. In particular, it is consistent with, and is plausibly a consequence of, paradigmatic reductionist views of testimony, which hold that testimonial knowledge and justification can be explained in terms of one's having a posteriori justification, deriving from non-testimonial sources like perception and induction, to believe that one's sources, or perhaps even sources of testimony in general, are sincere and reliable. ${ }^{4}$

Even so, in explaining the naive theory I have been careful to remain neutral on an especially controversial commitment of reductionism that has been the principal focus of many of its critics: that one can be justified in believing that one's sources are reliable only on the basis of a posteriori evidence (see, e.g., Burge 1993 and Coady 1992). For it is consistent with the naive theory that one's justification to believe that one's sources are sincere and reliable need not derive from a posteriori evidence. It is open to the naive theorist to claim, for example, that one has a default entitlement to believe that one's sources are sincere and reliable, even in the absence of positive evidence supporting their reliability. ${ }^{5}$

Instead of this controversial matter, I wish to focus on another that cuts across itthat of whether the justification of your belief depends solely on internal factors like your background justification concerning the source's reliability, or instead also depends on external factors like whether your source is objectively reliable. To get a better grip on this question we can consider an example:

Two Sources: Sherlock says that $\mathrm{p}$ and Clouseau says that $\mathrm{q}$ (where $\mathrm{p}$ and $\mathrm{q}$ are independent). Sherlock is in fact reliable and justified, while Clouseau is unreliable and unjustified. But your evidence does not favor the reliability or justification of either source over the other. You believe both Sherlock's testimony that $\mathrm{p}$ and Clouseau's testimony that $\mathrm{q}$.

Notice that Two Sources is schematic in that it does not specify whether you have justification to believe that your sources are reliable or justified in their beliefs. Instead, it specifies only that whatever evidence you have does not favor one source over the other. This allows me to characterize two kinds of views about Two Sources in a way that remains

\footnotetext{
${ }^{3}$ Here and elsewhere, I use 'justification' broadly, to cover justification stemming from evidence or argument, as well as any justification one might be thought to have by default (i.e., 'entitlement'), or from non-inferential sources such as perception. The naive theory is thus consistent with the view that one can justifiably believe a source's testimony even without evidence that the source is reliable, so long as one has non-evidential justification to believe that the source is reliable.

${ }^{4}$ Hume (1993 [1777], Sec. 10) is often regarded as the classic exponent of reductionism, and Harman (1965), Lipton (1998 and 2007), Malmgren (2006), and Schiffer (2003) offer more recent, sometimes more qualified, forms of reductionism. See Adler 2014 for a helpful review.

5 It should be noted that the naive theory as I have formulated it is not consistent with the closely related view that one has default entitlement to trust particular items of testimony, but not to believe that one's source is reliable in general. Even so, the differences between this view and the naive theory will be inessential for our discussion. See fn. 25 below for a related point about memory.
} 
neutral on the question of whether you can justifiably believe a source's testimony without background justification to believe that the source is reliable.

For a given way of filling in the details of the case, let's say that a symmetrical verdict is one that says your belief that $\mathrm{p}$ and your belief that $\mathrm{q}$ are equally justified, either by saying either that both of your beliefs are justified or that neither are. An asymmetrical verdict is one that says instead that they are unequally justified - most plausibly, by saying that your belief based on Sherlock's testimony is justified, while your belief based on Clouseau's is not. We can now distinguish between two broad and potentially heterogeneous classes of theories of testimony. On the one hand, there are theories that always give symmetrical verdicts, no matter how the details of the case are filled in. Call these symmetrical theories of testimony for short. The naive view is an example of a symmetrical theory, since it says that whether you are justified in believing a source's testimony does not depend on the source's actual reliability or justification, but instead on your background justification to believe that the source is reliable and sincere. On the other hand, there are theories that sometimes give asymmetrical verdicts, depending on how the further details of the case are filled in. Call these asymmetrical theories of testimony. Asymmetrical theories say that at least sometimes the justification of one's own belief depends on the actual reliability or justification of one's source, while symmetrical theories say that the justification of one's beliefs never depends on those kinds of factors.

One familiar example of an asymmetrical theory is reliabilism, which says roughly that in the absence of defeaters your justification to believe what a source says depends on its objective reliability. Concerning Two Sources, the reliabilist says that if you believe both that $\mathrm{p}$ and that $\mathrm{q}$, your belief that $\mathrm{p}$, which has as its source the reliable Sherlock, will be justified, while your belief that q, which has as its source the unreliable Clouseau, will be unjustified. 6

Reliabilism yields asymmetrical verdicts about cases involving a wide range of sources, from other people to measuring devices like a fuel gauge or a thermometer. But the asymmetrical rival to my preferred naive theory that will be our primary focus here, transmissivism, is more specific to the epistemology of testimony from other people. The transmissivist joins the reliabilist in saying that the justification of your beliefs depends on the objective credibility of your source. But according to the transmissivist, what matters is not whether the source is reliable but instead whether the source's own belief is justified. The transmissivist's basic idea is that in the absence of your own reasons for believing that $\mathrm{p}$, you can, through the testimony of a source who tells you that $\mathrm{p}$, hold a belief that $\mathrm{p}$ that is justified (if at all) by the source's reasons rather than your own. In the jargon, the point is sometimes put by saying that the justification of a source's belief is transmitted along with the belief itself to the recipient of the source's testimony.

Transmissivism as I have formulated it is a striking view. To be sure, it is very plausible that a source's reasons can affect whether one acquires knowledge from that source's

\footnotetext{
6 Whether familiar kinds of reliabilism entail this type of reliabilism about testimony will depend on how belief-forming methods are individuated. On a very coarse-grained individuation of methods, both of your beliefs in Two Sources are formed by the same coarsely individuated method (i.e., trusting testimony). A reliabilist who individuates methods this coarsely is not committed to the kind of reliabilism about testimony that I will discuss here. However, I suspect that no matter how the reliabilist individuates methods, there will be cases with the same general structure as Two Sources about which she will be committed to asymmetrical verdicts.
} 
testimony. If you are told that $\mathrm{p}$ by a source who believes $\mathrm{p}$ for no good reason, then, barring exceptional circumstances, your belief that $\mathrm{p}$ will not amount to knowledge. But the transmissivist goes further, and says that a source's reasons matter for whether one's belief is even justified. It is admittedly difficult on a first pass to make sense of the idea that the justification of one's own belief can depend on the reasons possessed by another person. Nevertheless, transmissivism is deserving of our attention, for at least two reasons. First, transmissivism has a number of prominent supporters. It has been advocated recently by David Owens (2000, Ch. 11) and Frederick Schmitt (2006), and it is natural to take Tyler Burge's classic work (1993 and 1997) to be committed to it. ${ }^{7}$ Second, and more importantly for our purposes, we will see in Section 3 that transmissivism is a natural counterpart to an attractive and, in my view, correct theory concerning the epistemology of memory. We should therefore evaluate transmissivism on its own terms now, so that we can see later on why its problems fail to extend to a corresponding view about memory. ${ }^{8}$

At least for theorists attracted to an externalist conception of justification, transmissivism has some prima facie appeal. For it is clear that in some sense your belief based on Sherlock's testimony has more going for it, epistemically speaking, than your belief based on Clouseau's testimony does. Although the beliefs are on a par so far as your own reasons are concerned, your belief that $\mathrm{p}$ has a kind of external corroboration from Sherlock's reasons that your belief that q does not receive from Clouseau's. This might be taken by the externalist to mean that your belief derived from Sherlock's testimony can have enough going for it to qualify as justified, even when your belief derived from Clouseau's does not. But some transmissivists have gone further, and claimed that even philosophers who are averse to strongly externalist theories like reliabilism can nonetheless accept

\footnotetext{
${ }^{7}$ Note that Owens goes on to qualify his view by claiming that there is a distinct "dimension of rationality" on which transmissivism is false, but the claims I advance here stand opposed even to this qualified version of Owens' view. Although Plantinga (1993, Ch. 4) argues for transmissivism about warrant, as he understands the term this commits him only to the claim that one's source's justification matters for whether one's belief can amount to knowledge. See Lackey (2008) for criticisms of this kind of view. Like Plantinga, Burge (1993 and 1997) focuses on the claim that a source's reasons matter for whether one's own belief can amount to knowledge, and the closest Burge comes to an endorsement of transmissivism about justification is equivocal (1997, fn. 2; see also Edwards, 2000 for discussion). But I think Burge is most naturally read as endorsing transmissivism about justification as well. When pressed by Christensen and Kornblith (1997), Burge is direct in endorsing a corresponding preservative view of memory (1997, pp. 37-39) that I discuss in greater detail in Section 3 below. An analogy between memory and testimony is a central theme in Burge's work, and Burge leans heavily on this analogy in motivating his central thesis that one can acquire a priori knowledge by testimony. It is therefore natural to take him to be committed to transmissivism about justification. It should be noted, however, that another central theme in Burge's work, the Acceptance Principle (1993, pg. 467), is on its own consistent with a symmetrical theory of testimony.

8 See also Malmgren 2006 for objections to Burge's view that are largely independent from those I develop below. Although the particulars of Malmgren's objections to Burge hinge on difficult exegetical matters, I take her to have raised an important general problem for any transmissivist who maintains that testimony can confer a priori knowledge. Burge's claim that one can acquire a priori knowledge of, say, a mathematical theorem from the testimony of a teacher is surely radical. But as Malmgren notes, it would seem indefensible for Burge moreover to claim that one can have a priori knowledge of the proposition that the teacher says the theorem is true, since this proposition concerns deeply contingent matters of fact. If one's knowledge of this proposition is admitted to be a posteriori, however, then this would seem to raise trouble for Burge's claim that one's knowledge of the theorem itself is a priori. For it would seem that the proposition that the teacher says the theorem is true is one's basis for belief in the theorem itself, and that, if so, one's belief in the theorem cannot be a priori. See fn. 33 below, for a potential response available to Burge.
} 
transmissivism's contention that your corroborated belief that $\mathrm{p}$ can be justified even when your uncorroborated belief that $\mathrm{q}$ is not. For the sense in which a corroborated belief has more going for it is not merely a matter of the objective reliability of its source. Instead, there is an important sense in which there are stronger reasons backing up a corroborated belief, even if those reasons are not always available to the agent herself.?

However, I think that this motivation for transmissivism, which identifies a belief's being justified with its having something going for it epistemically, misses something important about the distinctive nature of justification ascriptions. In calling a belief 'justified' or 'unjustified', we do not merely attribute to the belief positive or negative epistemic characteristics, as externalists sometimes suggest (e.g., Plantinga 1988 and Goldman 1986, 20-26). We moreover issue a kind of recommendation in favor of or against holding the belief. To say that a belief is justified in a given situation is to recommend holding the belief as the epistemically appropriate thing for an agent in that situation to do -i.e., as the thing that such an agent ought to do, epistemically speaking. Correspondingly, to say that a belief is unjustified in a given situation is to recommend against holding that belief, and in favor of withholding belief instead.

There are many ways that the rough idea that justification ascriptions go along with recommendations to hold or withhold belief might be developed. There is room among philosophers sympathetic to this idea for disagreement about whether the kind of epistemic recommendations at issue ever take wide scope over conditionals, ${ }^{10}$ about whether they are best understood as imperatives or as normative propositions, ${ }^{11}$ and about what it means for an agent to follow them. ${ }^{12}$ And as I will explain below, there is further room for disagreement on the question of whether the recommendations that go along with justification ascriptions should be thought of as permissions or as prohibitions, and whether we ever can be epistemically permitted to adopt a doxastic attitude without being prohibited from adopting others. ${ }^{13}$ For the most part, however, we can bypass these difficult issues here. As we will see, the commitments of my central argument against transmissivism are quite modest ones, and are likely to be accepted by anyone broadly sympathetic to understanding justification in terms of what one epistemically ought to believe, what one is

9 Owens (2000, 133-134) emphasizes this point in attempting to distance his transmissivist view from reliabilism.

10 See, e.g., Broome 1999 and 2005 and Kolodny 2005. It should be noted that disagreements between widescopers and narrow-scopers are sharpest when it comes to cases, unlike those at issue here, in which an agent already holds one or more irrational attitudes. Even concerning these controversial cases, narrow-scoper Kolodny still rejects the view that ascriptions of rationality and irrationality are "purely evaluative," and unconnected to recommendations. On Kolodny's view, to say that a belief is rational for an agent is to recommend holding the belief, but in a way that is relativized to the agent's point of view.

11 See, for example, Boghossian's (2008, Section 1) discussion of whether epistemic rules should be understood as normative statements or as imperatives.

12 See Goldman (1999) for a critical and I think uncharitable discussion of the idea that facts about justification should guide us in our beliefs_-although as Goldman notes, some proponents of the idea have unfortunately understood it in just the way Goldman criticizes. For discussions with which I am more sympathetic, see Boghossian 2008 and Pollock and Cruz 1999, Ch. 5.

13 See, e.g., Schoenfield 2014, White 2005, and Boghossian, 2008, Section 1. 
permitted to believe, what one is rationally required to believe, and so on-and even by some who are hostile to these ways of understanding justification.

The rough idea behind the argument against transmissivism is this: If we follow the transmissivist in saying that your beliefs in Two Sources are asymmetrically justified, then it is difficult to avoid the unattractive consequence that asymmetrical doxastic attitudes could be justified. More specifically, if we say that you are justified in believing Sherlock's testimony that $\mathrm{p}$ but unjustified in believing Clouseau's testimony that q, then it is difficult to avoid the consequence that you could be justified in jointly believing that $\mathrm{p}$ and withholding belief from $\mathrm{q}$. And this consequence is implausible because believing that $\mathrm{p}$ while withholding belief from $\mathrm{q}$ involves flagrant irrationality, since by stipulation you have no reason to take Sherlock's testimony to be more credible than Clouseau's. ${ }^{14}$

The argument is most easily developed if we help ourselves to some potentially controversial assumptions regarding the nature of the epistemic recommendations at issuenamely, that they involve claims about what one ought to believe, and that these claims sometimes take wide scope over conditionals. For given the former assumption, we should take asymmetrical theories like transmissivism to be committed to the claim that one ought to believe Sherlock's testimony that $\mathrm{p}$ and that one ought not to believe Clouseau's testimony that $\mathrm{q}$ - that is, that Ought-Bp \& Ought- $(\sim \mathrm{Bq})$. The argument against this claim appeals to two premises, the first of which is that if you ought not to believe that $\mathrm{q}$, then you ought instead to withhold belief from q-that is,

(1) Ought- $(\sim \mathrm{Bq}) \supset$ Ought-Wq.

This premise is plausible, because for any proposition that one considers, one must either believe it or withhold belief from it. So in recommending against one's holding a belief, one recommends withholding belief instead.

The second premise appeals to the intuition that it would be flagrantly irrational for one who is aware of no reason to trust Sherlock over Clouseau nevertheless to believe Sherlock's testimony that $\mathrm{p}$ while withholding belief from Clouseau's testimony that $\mathrm{q}$. Since it is plausible that one ought not to be flagrantly irrational, it plausibly follows that one ought not to believe that $\mathrm{p}$ while withholding from $\mathrm{q}$ - that is,

(2) Ought-[ (Bp \& Wq)].

It is a familiar principle of deontic logic that one cannot have logically incompatible obligations, and thus that if Ought- $(\sim A)$, then $\sim$ Ought-A. And it is furthermore familiar that the obligation operator aggregates over conjunction, such that if Ought-B \& Ought- $C$, then Ought-(B \& C). It therefore follows from (2) that

$$
\text { (3) } \sim(\text { Ought-Bp \& Ought-Wq). }
$$

From (1) and (3), it follows that

$$
\text { (4) [Ought-Bp \& Ought- }(\sim \mathrm{Bq})] \text {, }
$$

\footnotetext{
14 See Huemer 2006 for an attempt to develop an objection to reliabilism that draws on what I take to be the same core insight. I am skeptical, however, that Huemer's argument supports his positive theory of justification, as I hope to discuss elsewhere.
} 
contrary to what asymmetrical theories like transmissivism hold.

In arguing against transmissivism in this way, we have helped ourselves to a number of potentially controversial assumptions. Firstly, we have assumed that the kinds of recommendations issued by justification ascriptions are obligations, rather than mere permissions. This assumption will be denied by permissivists about justification, who otherwise are sympathetic to the idea that justification ascriptions go along with recommendations of a sort. Secondly, we have assumed that one ought to be rational, and thus that one ought not to believe that $\mathrm{p}$ while withholding belief from $\mathrm{q}$. This assumption might be denied by some externalists, who might simply deny any connection between rationality and what one ought to believe. But it might furthermore be denied by narrowscopers like Niko Kolodny (2005), who accept a more limited connection between rationality and what one ought to believe, even while denying that one ought to be rational I think the assumptions hostile to permissivists and narrow-scopers are inessential to the argument. After explaining why, I will return to the potentially more serious challenge from externalists.

In motivating premise (1), we have assumed that one is obligated to believe what one is justified in believing, as permissivists would deny. But even if we instead hold that one is merely permitted to believe what one is justified in believing, it remains plausible that if you are not justified in believing Clouseau's testimony, then you must be justified in withholding belief from it. This follows from the more general thesis that

Existence: Given one's total evidence, there exists at least one justified doxastic attitude that one is in a position to take to any proposition. ${ }^{15}$

Like the stronger Uniqueness thesis that it is modeled on (White, 2005), the Existence thesis makes reference to a plurality of doxastic attitudes that one is in a position to take to a proposition. Traditionally, philosophers have acknowledged three such attitudes: belief, disbelief, and suspended judgment. But more recently, many theorists have wanted to expand the range of doxastic attitudes, either by including a continuum of degrees of confidence, ${ }^{16}$ or by distinguishing between a state of deliberately refraining from adopting a belief and that of merely failing to arrive at a view. ${ }^{17}$ We do not need to decide whether to countenance doxastic attitudes beyond the traditional three. Instead, we can simply employ the notion of withholding belief in a liberal way, such that an agent counts as withholding belief from a proposition if she has any doxastic attitude to that proposition other than belief. For our purposes, the important upshot of the Existence thesis is simply that if you cannot justifiably believe a proposition, then you can justifiably withhold belief.

15 I discuss the Existence thesis in more detail in Barnett 2014. Richard Feldman (2005, 282-283) appeals to a similar principle in his discussion of forgotten evidence cases of memory, though I think the principle's application to these cases is less straightforward than Feldman makes it out to be.

16 Since the support that one's reasons provide for a proposition can come in degrees, those who also allow for confidence to come in degrees should presumably say that one ought, epistemically speaking, to proportion one's degree of confidence in a proposition to the degree to which one's reasons support it. While I think we should accept this graded picture of justified credence, I will not assume it in what follows. Thanks to an anonymous reader for pressing me on this issue.

17 See, e.g., Bergmann 2005. Note that Bergmann uses the term 'withholding belief' to refer to the state of deliberately refraining from adopting a belief, whereas I will use it more broadly to encompass any case in which an agent does not adopt a belief that the proposition is true. 
It should be stressed that the Uniqueness thesis, the thesis on which the Existence thesis is modeled, remains controversial. But unlike the stronger Uniqueness thesis, which says that there is always exactly one justified doxastic attitude that one can take to any proposition, the Existence thesis is consistent with a permissivist view of justification on which multiple doxastic attitudes sometimes can be justifiable given a single set of evidence. The Existence thesis thus stands opposed only to the possibility of epistemic quagmiressituations in which no doxastic attitude could be justified. ${ }^{18}$ This makes Existence difficult to reject if we accept that justification ascriptions go along with epistemic recommendations. If you consider whether a proposition is true, then you must take some doxastic attitude to the proposition. So if we recommend against your believing the proposition, it seems inconsistent for us also to recommend against your withholding belief from it.

Even so, Existence stands in need of an important qualification. In denying the possibility epistemic of quagmires, the Existence theorist does not deny the possibility of your being psychologically incapable of adopting a justified attitude. If a reason-impairing drug has left you incapable of seeing the obvious consequences of your evidence, the Existence theorist can grant that there is a sense in which you cannot adopt a justified belief in those implications. Even so, there remains an important sense in which, despite your inability to make use of the evidence available to you, you still are in a position justifiably to believe the implications of your evidence. It is this sense that the Existence theorist has in mind when he says that there always is a justified attitude that you are in a position to take toward any proposition. This important qualification of Existence offers little relief to the transmissivist, however, who in denying that your belief in Clouseau's testimony is justified wants to deny that you are even in a position to justifiably believe his testimony. ${ }^{19}$

The argument against asymmetrical theories like transmissivism also assumes that justified doxastic attitudes are obligatory in moving from (2) to (3). Recall that this move appeals to the plausible principle that obligations aggregate over conjunction, such that if one is obligated to believe $\mathrm{p}$ and obligated to withhold from $\mathrm{q}$, then one is obligated to jointly believe $\mathrm{p}$ and withhold from q. A corresponding principle is far less plausible for mere permissions, but for reasons that I think are unlikely to be of help to the transmissivist. The permissivist might contest the aggregation principle by claiming that even if your evidence permits a range of doxastic attitudes towards each of a pair of propositions, the attitude that you in fact take to one of those propositions can further constrain the attitudes you justifiably can take to the other. For example, the permissivist might think that given ambiguous meteorological evidence, you can justifiably believe both the proposition that it will rain and the proposition that it will be cloudy, and you also can justifiably withhold belief from both of these propositions, even though you cannot justifiably jointly believe that it will rain and withhold belief that it will be cloudy. The reason why I doubt that this move will help the transmissivist is that the transmissivist does not think that you could justifiably adopt a range of attitudes toward Clouseau's testimony that $\mathrm{q}$ in the first place. Since the transmissivist must say that you can be justified only in withholding belief from Clouseau's testimony that q, it does not appear open to the transmissivist to say that by

18 For recent supporters of epistemic quagmires, see Avnur 2012, Christensen 2010, and Jackson 2011. The issue is naturally seen as a counterpart to an older and better known debate in ethics over the possibility of moral quagmires (or dilemmas). See McConnell 2010 for a recent review.

${ }^{19}$ Cf. Owens (2000, p. 141), who treats cases of unsubstantiated testimony as akin to deficits of reasoning and memory. 
doing so you make unavailable to yourself an otherwise justifiable attitude of belief to Sherlock's testimony that $\mathrm{p}$.

The argument against transmissivism might also be resisted by narrow-scopers like Kolodny, who deny that we have a standing obligation to be rational. Recall that in motivating (3), we appealed to (2), which says that one ought not to believe that $\mathrm{p}$ and withhold from $q$ on account of the irrationality of adopting these attitudes jointly. The claim that one ought not to believe $\mathrm{p}$ and withhold from $\mathrm{q}-$ i.e., that Ought- $[\sim(\mathrm{Bp} \& \mathrm{Wq})]$ -is equivalent to a controversial wide-scope rational requirement that Ought-(Bp $\supset \sim \mathrm{Wq})$. Narrow-scopers resist such claims, because they deny that one has standing obligations to avoid irrational sets of attitudes. But their rejection of standing obligations to avoid irrational attitudes is compatible with a weaker assumption that is sufficient to motivate (3). The weaker assumption is simply that we are never obligated to adopt irrational attitudes. This weaker assumption is sufficient to motivate (3), which holds only that you are not both obligated to believe Sherlock's testimony that $\mathrm{p}$ and to withhold from Clouseau's testimony that q. And this weaker assumption should not be objectionable to narrow-scopers, who are happy to accept, in place of putative wide-scope requirements, corresponding claims in which the obligation operator takes narrow scope. There is thus nothing in the narrowscoper's view that would prevent him from accepting the claim that Ought-Bp $\supset$ Ought$(\sim \mathrm{Wq})$, from which (3) follows under the plausible assumption that if Ought- $(\sim \mathrm{Wq})$, then $\sim$ Ought-Wq. ${ }^{20}$

So far we have considered objections to the argument against transmissivism from friendly sources, who agree in general terms that justification ascriptions go along with recommendations as to what to believe, and that these recommendations are at least constrained by what one can rationally believe in the limited way necessary to motivate (3). But what about a more radically externalist response, which simply rejects that what one is justified in believing is constrained by what one can rationally believe?

It should be noted that a wholesale rejection of a connection between rationality and justification is a more radically externalist posture than transmissivists have typically taken their view to commit them to. Indeed, there are limits to how far even committed externalists like reliabilists have been willing to allow the justification of an agent's belief to come apart from the reasons available to the agent herself. As is now familiar, even staunch externalists have included a 'no defeaters' provision in their accounts of justified belief, and transmissivists have followed suit. ${ }^{21}$ The purpose of these provisions is to avoid allowing an agent to be justified in believing the testimony of an objectively reliable source when the agent herself has strong reasons to believe that the source is not reliable. Asymmetrical theorists of all stripes have thus allowed the objective epistemic credentials of a source's testimony to make a difference to the justification of an agent's belief only at the margins, when the agent lacks strong reasons of her own. Even so, I think that when we turn from cases involving a single belief from a single source to cases like Two Sources, it is clear that a 'no defeaters' provision fails to avoid licensing doxastic attitudes that are irrational by the agent's own lights. For even if the asymmetrical theorist avoids licensing attitudes that are irrational taken on their own, she still is committed to licensing combinations of attitudes

\footnotetext{
20 I thank an anonymous reader for pressing me on this issue.

21 While all transmissivists allow for defeating evidence to undermine a belief's extended corroboration, the point is especially prominent in Burge (1993 and 1997).
} 
that strike us as equally irrational because they discriminate between sources that from the agent's perspective appear equally credible. By joining with fellow asymmetrical theories like reliabilism in licensing such combinations of attitudes as justified, the transmissivist thus falls into traditional problems for externalist theories, despite the protest of some transmissivists that their view retains internalism's core connection between justification and reasons (e.g., Owens, 2001, 133-134).

But there are further problems for a transmissivist who seeks to defend his view by severing justification from rationality, beyond its commitment to a stronger kind of externalism than transmissivists have traditionally accepted. The central problem with this or any similar response on behalf of transmissivism is that it robs the view of its core source of motivation, which comes from an alleged analogy between memory and testimony. ${ }^{22}$ As we will see in Section 3 below, when we turn our attention from testimony to memory, we find that a natural counterpart to transmissivism, which I call preservativism, has considerable appeal. Transmissivists have appealed to a natural, but in my view mistaken, analogy between memory and testimony to support their view that testimony can transmit a source's justification for a belief to its recipient, claiming that if we accept preservativism about memory, this should lead us to accept transmissivism as well. But as we will see, accepting preservativism requires no corresponding rejection of the view that one cannot justifiably adopt irrational beliefs.

\section{Memory}

It is natural when discussing the epistemology of memory to focus on tricky cases where the initial storage and subsequent retrieval of information from memory plays a conspicuous role: cases involving fuzzy memories of episodes from the distant past, or in which one has forgotten the reasons that led one to believe a conclusion that one still remembers, or in which the reliability of one's memory is in question. Here I will focus instead on easy cases in which you retain both a belief and the evidence that it is based on over a relatively short period of time, and in which no reason to doubt the reliability of your memory arises. So when I speak of a case of memory I mean any case where a person comes to believe something at one time and continues to believe it until a later time, without having forgotten or changed her mind in the time in between. And when I speak of the faculty of memory I am speaking broadly of the psychological mechanisms, whatever they may be, that typically enable this maintenance or preservation of belief over time. When you learn that the MoMA is on 53rd St. on Monday and then later on Wednesday take a left on 53rd St. to go to the MoMA, that is a case of memory. And when the detective in Detective Story concludes that it was Plum who committed the murder and then later on

22 The alleged analogy between memory and testimony plays a major dialectical role in the argument's of Burge (1993), Owens (2000), and Schmidt (2006). But it should be noted that some transmissivists, most prominently Owens, claim as further motivation their view's apparent anti-skeptical implications, alleging that one cannot give a philosophically satisfying reply to skepticism about testimony without accepting their view that our testimony-based beliefs can be justified by the reasons possessed only by our sources. But I think that restricting transmissivism to a kind of justification (or 'justification') disconnected from rationality substantially weakens the anti-skeptical motivation for transmissivism as well. For such a restricted form of transmissivism will be of no assistance in combatting skeptical worries that it is irrational for us to believe the things we do on the basis of testimony. This is especially troubling if we accept that rational belief is a necessary condition for knowledge. For if so, it would seem that transmissivism could at best help with skeptical worries that our ordinary testimony-based beliefs are Gettier cases, in which one rationally believes the truth, and yet still fails to know. 
reports this conclusion to the chief, that too is a case of memory. Cases of memory thus are not limited to cases involving episodic memories, but instead include all cases where belief or knowledge is preserved over time.

Regarding testimony from another person, we have considered a transmissivist view that says that the epistemic status of the belief can be transmitted through testimony along with the belief itself. The preservativist makes a corresponding claim about cases of memory: that the epistemic status of a belief can be preserved along with the belief itself in memory. ${ }^{23}$ In the ordinary cases of memory at issue here, preservativism can seem very attractive, even obvious. When the detective comes to believe that it was Prof. Plum based on some clues, whether his belief is justified depends on whether the clues really are good reasons to believe that it was Plum. When he later reports to the chief that is was Plum without recalling the clues themselves from memory, we think that the justification of his belief continues to depend on whether the clues themselves are good reasons to believe that it was Plum. Any complete theory of the epistemology of memory will have to go beyond the apparently easy cases like this. But here I will contrast preservativism with an extreme view that says that preservativism gets things wrong in even what appear to be the easy cases.

The view that I have in mind is a natural counterpart to the naive theory of testimony. Since a diary is a means of conveying testimony from one's past self to one's present self, I call the theory that treats memory on the model of what we naively want to say about testimony the diary model of memory. The naive theory of testimony says that even when you receive testimony whose content is that $\mathrm{p}$, what you learn first is not $\mathrm{p}$ itself but rather that the source in question says that $\mathrm{p}$. And the diary model of memory correspondingly says that when you seem to remember that $\mathrm{p}$, what happens first is that you become aware of the psychological fact that you currently seem to remember that $\mathrm{p}$. Whether this puts you in a position to be justified in now believing that $\mathrm{p}$ will depend solely on whatever background justification you have concerning the reliability of what you seem to remember, ${ }^{24}$ just as for testimony your justification to believe your source's testimony depends solely on your background justification concerning the reliability of your source. In ordinary cases of testimony, the reliability of a source's testimony that $\mathrm{p}$ depends both on the reliability of what she says as an indicator of what the source believes and the reliability of what the source believes as an indicator of what is true. Similarly, it is common knowledge that in ordinary cases of memory the reliability of your apparent memories depends both on the reliability of memory itself as a record of your prior judgments and on the reliability of your prior judgments as an indicator of the truth. Since this is common knowledge, the diary theorist says that in ordinary cases, whether you are justified in believing what you seem to remember depends on your having background justification (or entitlement) to believe both that your apparent memories are a reliable indicator of your prior judgments and that your prior judgments are a reliable indicator of the truth. In saying

\footnotetext{
23 Preservativism has been widely discussed, but I am especially indebted to discussions from Tyler Burge (1993 and 1997) and David Owens (2000, Ch. 10).

24 An anonymous reader asks whether the diary theorist should take the justification of a particular memory belief to depend on one's background justification concerning the reliability of one's memory in general, or instead concerning its reliability in some more specific context. The diary theorist owes us an answer to this question, but I think he is in no worse shape than anyone else. For we all should agree that, e.g., one's justification to believe the reading of a fuel gauge can depend on one's background justification concerning the reliability of the fuel gauge. And similar questions arise for that case as well.
} 
all this, the diary model treats memory as a means of gaining evidence about one's former judgments in much the way that we naively take ordinary testimony to serve as a way of gaining evidence about the beliefs or judgments of another person. The diary model thus treats recalling information from memory as akin to acquiring testimony from one's former self-like reading the entries in one's long-lost diary. ${ }^{25}$

It is worth emphasizing that in accepting an analogy between memory and a diary, the diary theorist does not merely deny, as many theorists do, that the justification of one's present belief can depend upon evidence that one has forgotten. ${ }^{26}$ The diary theorist goes further and denies that the justification of one's belief can depend on evidence that is still stored in memory but is merely not occurrently accessed. In saying this, the diary theorist is making an extreme and controversial claim. But this claim is arguably what we should say if we take seriously the analogy between ordinary memory and a diary. When the detective in Sequel reads in his diary that it was Plum who committed the murder, we think that the justification of his belief does not depend on whatever clues appear on unread pages of his diary. This is because we think that the justification of an agent's beliefs depends on the reasons the agent has, and not on whatever reasons the agent would easily be able to acquire. ${ }^{27}$ Similarly, the diary theorist says that the justification of a conclusion you recall from memory depends only on whatever reasons you actually recall, and not on whatever further reasons you could recall but do not. ${ }^{28}$

These commitments make the diary model a striking view. But it is nevertheless deserving of our attention for several reasons. Firstly, it has behind it a tradition of prominent supporters, going back at least to Descartes, and continuing on through more recent theorists like Roderick Chisholm, Richard Feldman, and John Pollock. ${ }^{29}$ Secondly, the diary model is the natural counterpart to the naive theory of testimony, and if we are to reject the prima facie appealing option of extending what we have said about testimony to ordinary cases of memory, then we should understand why. And finally, even though it is false, I think the diary model contains important insights that will figure into a positive account of some hard cases of memory that involve memory failures, forgotten evidence, and evidence against the reliability of your apparent memories. To know what we should say

\footnotetext{
25 One closely related view says that it is your apparent memory itself, rather than your awareness of its occurrence, that justifies you currently in believing that p. This view might also be coupled with the further claim that one's apparent memories justify beliefs even in the absence of justification to believe that one's apparent memories are reliable, so long as one lacks justification to believe that they are unreliable. Such a view would have much in common with Pryor's (2000) dogmatism about perceptual justification, but with apparent memories in place of perceptual experiences. Although the differences between this and the standard version of the diary model are important, my criticisms of the diary model will apply equally to both views — and to any view that holds that one's justification to believe what one seems to remember depends solely on the state of one's background justification concerning the reliability of one's apparent memories.

26 Theorists who deny this claim include Dogramaci (MS), Feldman (2005), and Harman (1973). Feldman elsewhere (2004) endorses the diary model.

${ }^{27}$ Cf. Gibbons' (2006) 'access externalism'.

${ }^{28}$ Feldman, 2004 is especially clear on this point.

29 See, e.g., Chisholm 1989, 29-30; Feldman 2004; and Pollock and Cruz 1999, 45-55. The discussion of memory in Pollock and Cruz 1999 is unchanged from an earlier edition of which Pollock is the sole author. I discuss the historical matter of Descartes's views elsewhere (Barnett, MS).
} 
about these hard cases, we first must understand what the diary model mistakenly says about even the easy cases.

One of the diary model's central commitments about even easy cases of memory is a natural counterpart to the naive theory's symmetrical implications concerning Two Sources. Consider:

Two Beliefs: On Monday you came to believe that $\mathrm{p}$ for good reasons that justified your belief, and on Tuesday you came to believe that $\mathrm{q}$ for bad reasons that failed to justify it (where $\mathrm{p}$ and $\mathrm{q}$ are independent). It is now Wednesday, and you have forgotten nothing, reconsidered nothing, and learned no new relevant evidence. You recall each conclusion without occurrently recalling your original reasons for those conclusions.

As with Two Sources, Two Beliefs is schematic in that it leaves unspecified your background justification to believe in your general reliability at reaching true beliefs and maintaining them in memory over time. Again we can distinguish between two broad classes of theories. The symmetrical theories of memory are those that say that no matter how these details are filled in, on Wednesday your belief that $\mathrm{p}$ and your belief that $\mathrm{q}$ are equally justified. And the asymmetrical theories of memory are those say that, depending on how the details of the case are filled in, it could be that on Wednesday your belief that $p$ is justified even though your belief that $\mathrm{q}$ is unjustified.

We have seen that the naive theory is a symmetrical theory of testimony because it says that your justification to believe a source's testimony depends on your own justification to believe that the source's testimony is reliable, rather than on whether the source actually has good reasons to believe what he says. Correspondingly, the diary model is a symmetrical theory of memory because it says that your justification to believe what you seem to remember depends on your current justification to believe that your apparent memories are reliable rather than on whether your initial reasons for accepting a recalled conclusion were good ones. In contrast, transmissivism is an asymmetrical theory of testimony because it says that the justification of Sherlock's justified belief that $\mathrm{p}$ and of Clouseau's unjustified belief that $\mathrm{q}$ can be transmitted along with the beliefs themselves through testimony. And correspondingly, preservativism is an asymmetrical theory of memory because it says that the justificatory status of your justified belief that $\mathrm{p}$ and your unjustified belief that $\mathrm{q}$ are preserved along with the beliefs themselves in memory.

We saw in Section 2 above that there are strong reasons to reject asymmetrical theories of testimony like transmissivism and reliabilism. For as we saw, it is difficult to say that your beliefs in Two Sources are asymmetrically justified without also saying that asymmetrical doxastic attitudes could be justified. This is a problem for asymmetrical theories of testimony because it is implausible that you could be justified in jointly believing Sherlock's testimony that $\mathrm{p}$ and withholding belief from Clouseau's testimony that $\mathrm{q}$. Since you are aware of no reason to trust Sherlock's testimony over Clouseau's, it seems patently irrational for you to do so-and it is unattractive to allow doxastic attitudes to qualify as justified despite this sort of patent irrationality. In contrast, asymmetrical theories of memory fare better. For unlike in a case of testimony like Two Sources, it is not implausible in Two Beliefs that asymmetrical doxastic attitudes could be justified. This is because on Wednesday you still have available the bad reasons that led you to believe that $\mathrm{q}$ to begin with. Since you therefore are in a position to justifiably give up your belief that $\mathrm{q}$, in saying that your Wednesday belief that $\mathrm{q}$ is unjustified the preservativist need not deny the 
Existence theorist's contention that if you are unjustified in believing a proposition then you must be in a position justifiably to withhold belief from that proposition. This is in stark contrast to the transmissivist, who says of Two Sources that your belief in Clouseau's testimony that $\mathrm{q}$ is unjustified even though you are in no position justifiably to withhold belief from q if you believe Sherlock's testimony that $\mathrm{p}$.

Not only does the connection between a belief's justification and the agent's own reasons for the belief fail to raise problems for preservativism (as it did for transmissivism), this connection also provides strong motivations in preservativism's favor. For if you believe that $\mathrm{p}$ on Wednesday for the same good reasons as you did on Monday, then your belief that $\mathrm{p}$ should still be justified on Wednesday. ${ }^{30}$ And if you believe that $\mathrm{q}$ on Wednesday for the same bad reasons as you did on Tuesday, then your belief that q should still be unjustified on Wednesday. In denying that your beliefs are asymmetrically justified on Wednesday, symmetrical theories like the diary model must therefore contend that your reasons for holding those beliefs have changed even though you have learned nothing, forgotten nothing, and learned no new relevant evidence in the meantime.

We will consider how the diary theorist might try to support this contention in Section 7. For now I want to emphasize only that however unattractive these commitments might make it appear, the diary model can at the same time seem obligatory if we turn our attention back to the epistemology of testimony. For we have seen the strong motivations behind symmetrical theories of testimony like the naive theory. And when we consider the initial appearances, it can seem that there is little difference epistemically between memory and testimony. So far I have tried to argue, against a strong temptation to the contrary, that there memory is not epistemically akin to testimony, since we should accept preservativism about the former and the naive theory of the latter. In the following sections I will consider some attempts to explain why memory and testimony differ in this way. In Section 4, I will consider and reject a candidate explanation that I suspect many philosophers otherwise would be attracted to. Then in Section 5, I will give my own preferred explanation.

\section{Testimony from one's former self}

In our discussion of Detective Story in Section 1, we considered a view which holds that the justification of one's memorial and of one's testimonial beliefs depend on different kinds of factors. Concerning testimony, this view says that when one comes to hold a belief via testimony, as the police chief in Detective Story does when he believes the detective's claim that it was Prof. Plum who committed the murder, the justification of one's belief does not depend even in part on whether one's source has good reasons for the belief, but instead only on one's own reasons for thinking that the source's testimony is reliable. This claim is the central thrust of the symmetrical naive theory of testimony. And concerning memory, the view says that when you retain a belief in memory, as the detective does when he initially concludes that it was Plum and then later reports his conclusion to the chief, the justification of your belief continues to depend on whether the reasons that persuaded you in the first place are good, so long as you learn nothing, forget nothing, and change your mind about nothing in the meantime. This is the central thrust of preservativism about memory. Thus anyone who accepts both the naive theory of testimony and preservativism

\footnotetext{
30 Here I assume that if a given set of reasons are good reasons to believe that $\mathrm{p}$ on Monday, then they will remain good reasons to believe that $\mathrm{p}$ on Wednesday.
} 
about memory most hold that memory and testimony differ epistemically in the way I have in mind.

The naive theory and preservativism on their own can appear superior to their principal competitors, transmissivism and the diary model. But it can appear puzzling how we might accept both the naive theory and preservativism together. For when we consider cases where one receives testimony from one's former self, such as when the detective in Sequel reads in his long-lost diary that it was Plum who committed the murder, it is natural to see similarities both to cases of testimony from another person and to cases of beliefs that are preserved in ordinary memory. So if we accept that memory and testimony from another person differ, then we are left with a dilemma. On the one hand, we could accept the analogy between testimony from one's former self and testimony from another person, in which case we must draw a line between memory and testimony from one's former self. On the other hand, we could accept the analogy between memory and testimony from one's former self, and instead draw a line between testimony from one's former self and testimony from another person.

In defending preservativism against the diary model of memory, I have already suggested some reason to favor the former option of drawing a line between memory and testimony from one's former self. But before expanding on what I already have said, I want to consider the alternative possibility of drawing a line instead between testimony from one's former self and testimony from another person. For sake of concreteness, I will consider what I take to be the most natural example of an account that does so, although my criticism of it will not depend on any details that might distinguish it from other possible accounts that draw a line in the same place. The account, which I extrapolate from rough suggestions that I have often received in conversation, is what I call the responsibility account, because it says that the crucial difference between memory and testimony from others lies in who bears responsibility for the belief's having something going for it epistemically.

The responsibility theorist identifies justified belief with belief for which the agent is blameless, and goes on to explain the epistemic differences between memory and testimony in terms of a difference in who's to blame if a belief lacks epistemic credentials. If you believe Clouseau's unjustified testimony that q, then depending on the circumstances you could be blameless for your belief's lack of external corroboration. So the responsibility account says, correctly, that you are no less justified in believing Clouseau's testimony that $q$ than you are in believing the justified Sherlock's testimony that p. If on the other hand you come to hold a belief for bad reasons and then retain that belief in memory, you have only yourself to blame for your belief's lack of corroboration. So the responsibility account says, again correctly, that you can be unjustified in your uncorroborated belief that q even while you are justified in your corroborated belief that $\mathrm{p}$.

Thus the responsibility account correctly yields both symmetrical verdicts about cases of testimony from other people and asymmetrical verdicts about cases of memory. Where it goes wrong, in my view, is in where it draws a line when distinguishing between them. We have seen that any account of the epistemic differences between memory and testimony must draw a line either between testimony from others and testimony from one's former self, or between testimony from one's former self and memory. The responsibility account takes the former course, since it says that justification goes with responsibility. If you unjustifiably believe a conclusion that you record in your diary, then upon later reading it you will have only yourself to blame should the conclusion have little going for it 
epistemically. In this way the responsibility account allows us to accept the analogy between memory and a diary that animated the diary model even without accepting the diary model itself. But in doing so the responsibility theorist runs into the same kinds of difficulties that the transmissivist faced. For consider:

Two Entries: Years ago, you believed that $\mathrm{p}$ for good reasons and you believed that $\mathrm{q}$ for bad reasons. You recorded both that $\mathrm{p}$ and that $\mathrm{q}$ in your diary along with your reasons. As time went by you forgot all about your beliefs and the reasons that led you to hold them. Today you find your diary, and you read the entry that says $\mathrm{p}$ and the entry that says $\mathrm{q}$ without reading the reasons that led you to believe these propositions in the first place. On the basis of what you have read, you believe both that $\mathrm{p}$ and that $\mathrm{q}$.

Like Two Beliefs and Two Sources before it, Two Entries is schematic in that it leaves unspecified whether you are justified in believing that your diary entries are reliable. As with those cases, we can distinguish between two potentially heterogeneous classes of theories: symmetrical theories, which say that you are equally justified in believing that $\mathrm{p}$ and that $\mathrm{q}$ no matter how these details are filled in, and asymmetrical theories, which say that depending one the details you can be justified in believing that $\mathrm{p}$ even while you are unjustified in believing that $\mathrm{q}$. The responsibility account is asymmetrical about this case of testimony from one's former self because, unlike the Two Sources case involving testimony from other people, you have only yourself to blame for the fact that your belief that $q$ has little going for it epistemically. Since the responsibility account identifies justified belief with blameless belief, it says that your blameworthiness for believing that $\mathrm{q}$ can make this belief unjustified even when your blameless belief that $\mathrm{p}$ is justified.

The responsibility account's asymmetrical verdict about Two Entries is unattractive for reasons that are by now familiar. If we follow the responsibility theorist in accepting that you are justified in believing that $\mathrm{p}$ but unjustified in believing that $\mathrm{q}$, then we will be forced to grant that you must be justified in jointly believing that $\mathrm{p}$ and withholding belief from $\mathrm{q}$. But when you read the two diary entries, one that says $\mathrm{p}$ and another that says $\mathrm{q}$, you cannot justifiably believe one of the entries but not the other unless you have some reason to favor one over the other. So the responsibility account, which is committed to an asymmetrical verdict about Two Entries, must be rejected.

\section{Rational explanation and the boundaries of the mind}

We have just seen reason to reject any account of the epistemic differences between memory and testimony that, like the responsibility account, draws a line between testimony from another person and testimony from one's former self. We now will consider what I view as the superior option of drawing a line between testimony from one's former self and memory. I call the account that I favor the rational explanation account, because it appeals to a tight connection between the justification of a belief and its rational explanation.

A rational explanation of a belief is a special kind of answer to the question 'Why do you believe that?' - an answer that cites the reasons or considerations that convince you that what you believe is true. When a detective comes to believe on the basis of some clues that it was Prof. Plum who committed a murder, for example, a rational explanation cites the detective's clues in explaining why he believes that it was Prof. Plum. We can follow convention in calling the relation between an agent's beliefs and the reasons that the belief is 
based on the basing relation. ${ }^{31}$ Although it is plausible that the basing relation is a species of causal relation, and that rational explanations are correspondingly a species of causal explanations, it is a familiar point that not all causal explanations of one belief in terms of other beliefs amount to rational explanations. ${ }^{32}$ When the chief of police believes the detective's testimony that it was Plum, the causal etiology of the chief's belief can be traced back to the detective's belief that it was Plum, and from there to the detective's beliefs about the clues. Nevertheless, this kind of interpersonal causal connection is not the right kind to underwrite a rational explanation of the chief's belief, since the chief's basis for believing that it was Plum cannot include clues known only to the detective. Although the detective's beliefs are part of the causal etiology of the chief's belief, the chief's reasons for the belief are the considerations that convince the chief that it was Plum-i.e., the fact that the detective says so, perhaps in addition to other evidence that the chief has regarding the detective's reliability.

The rational explanation account handles the epistemic differences between memory and testimony by appealing to the different ways in which ordinary memory and a diary each contribute to the rational explanation of an agent's beliefs. When the detective in Sequel reads in his long-lost diary that it was Prof. Plum who committed the murder, he comes to hold a belief that by stipulation he did not hold shortly beforehand. Intuitively, we want to say that when he does so he believes that it was Plum on the basis of his diary's saying so, just as the chief of police would if he were to read the same entry in the detective's diary. In contrast, memory typically serves to maintain one's beliefs along with the reasons on which they are based on over time. When you recall from memory the name of a close friend, you do not come to hold a new belief about what your friend's name is. Instead, you merely bring to your attention a fact which you have believed for some time, even when you are not attending to it. During the times when you are not attending to it, your belief about your friend's name is not held on the basis of facts about what you seem to remember regarding your friend's name, for at those times you do not seem to remember anything regarding your friend's name. So when you go on to recall your friend's name from memory, it is implausible that the basis for your belief about the friend's name is a fact about what you currently seem to remember. For it is implausible that the bases for your standing beliefs change dramatically from one moment to the next, depending on what you are attending to. Similarly, it is implausible that the detective's reasons for believing that it was Plum change dramatically depending on where he turns his attention. When he first comes to believe that it was Plum, he does so on the basis of his clues, and these clues continue to be his reasons while his attention turns elsewhere. So when he later reports to the chief that it was Plum by recalling it from memory, we should grant that his basis for the belief is still the clues

\footnotetext{
31 Sometimes in talking of an agent's reasons for a belief, theorists refer not to facts or propositions but instead to the agent's beliefs regarding those facts or propositions. Here it can be difficult to distinguish mere terminological differences from more substantive disagreement, but at any rate I doubt that even substantive disagreements about the metaphysics of reasons will matter for our purposes. John Turri (2009) has a recent discussion with a helpful review.

32 Although it is widely acknowledged in discussions of the basing relation that mere causation is insufficient for basing, typical examples of causation without basing involve intrapersonal Rube Goldberg-like processes whereby one's believing that $q$ causes one to believe that $\mathrm{p}$ without one's believing that $\mathrm{p}$ on the basis of $\mathrm{q}$. But our interest here is not these Rube Goldberg-like causal connections but instead mundane causal connections that typically obtain interpersonally in cases of testimony. See Turri 2011 and Wedgwood 2006 for recent discussions of the basing relation.
} 
themselves and not facts about what he seems to remember. This stands in stark contrast to the situation years later in Sequel, when the detective reads in his diary that it was Plum. For it is plausible that his reasons change when he forgets that it was Plum and then comes to believe it again upon reading his diary.

The rational explanation account takes this difference in the metaphysics of memory and a diary to underwrite downstream epistemic differences. Radical views like transmissivism to one side, we ordinarily take it for granted that the reasons that justify your belief, if it is justified, must be the very same reasons that explain why you hold that belief. Even if there are perfectly good reasons to believe that p 'out there,' we think that your belief that $\mathrm{p}$ will be unjustified if your reasons for holding the belief are not good ones. The transmissivist denies this identification of the reasons that explain your belief and the reasons that justify it, for the transmissivist thinks that the latter can include reasons known only to your source. ${ }^{33}$ And this means that the transmissivist must allow you to be justified in adopting doxastic attitudes like beliefs even if you do not do so for good reasons. In contrast to radical views like transmissivism, the rational explanation account of the epistemic differences between memory and testimony takes there to be a tight connection between justification and rational explanation, along roughly the following lines:

Connection: Any belief that is justified by reasons is justified by the reasons for which the agent herself holds the belief.

This claim is intended only as a first approximation of the kind of commitment that the rational explanation account brings with it. But even so, it should be clarified in a number of ways. First, Connection is restricted to beliefs that are justified by reasons in order to leave open the possibility of beliefs that are justified in a way that does not derive from reasons that the agent herself or anyone else possesses for the belief. (Some might claim this of perceptually justified beliefs, for example, or of beliefs that are allegedly justified by default.) It is plausible that if we accept Connection, then we also should accept corresponding claims about at least some cases of beliefs that are justified otherwise than by reasons. For example, it is plausible that if we accept Connection, we should accept that if a belief is immediately justified by perceptual states, then it must be immediately justified by the agent's own perceptual states. I will not explore the matter further here, however. The second point of clarification concerns what makes a given set of reasons good reasons for believing that p. For our purposes here, all we must assume is that whether a source's saying that $\mathrm{p}$ is a good reason to believe that $\mathrm{p}$ does not depend on whether the source has good reasons to believe that $\mathrm{p}$. Without this assumption, an asymmetrical theory of testimony could get in through the back door, as it were. We saw general arguments against such asymmetrical theories in Sections 2 and 4. I think it is possible to generalize this style of

33 Cf. Malmgren (2006, 226-230), who in effect takes the transmissivist Burge to be committed to denying that one's basis for believing an item of testimony are propositions about what the source has said. I think Burge might instead deny what I below call Connection, which holds that the reasons justifying a belief must be the same as those which form the agent's (psychological) basis for the belief. This could allow him to grant that one's basis for believing an item of testimony include propositions about what the source has said that one knows only a posteriori, even while the justification of one's belief in the testimony comes solely from the source's (potentially a priori) reasons. 
argument further into an argument that whether a reason is good can depend only on internal factors, but it is not necessary to do so here. ${ }^{34}$

By invoking Connection, the rational explanation account can offer us a satisfying explanation of why the justifications of memory and of testimony beliefs depend on different factors. In an ordinary case of testimony like Detective Story, the reasons for which the police chief believes that it was Prof. Plum who committed the murder are limited to things known (or at least believed) by the chief, such as the fact that the detective says that it was Plum, and perhaps that the detective is likely to be sincere and reliable. ${ }^{5}$ In contrast, we want to allow that the detective's reasons for believing that it was Plum can include the detective's clues, even when the detective is not occurrently recalling them. I take this to be because the detective still knows, and hence still believes, the clues even when he is not occurrently recalling them, and thus that the clues themselves can still be among his reasons for believing that it was Plum.

Because what one's reasons are can depend in this way on what one believes, the rational explanation theorist draws a line epistemically between memory and testimony in a place that corresponds to the boundary between what is internal and what is external to the mind of the believer. For in our naive ascriptions of beliefs, we take these mental states to depend on what an agent has stored 'internally' in memory. Even if two agents are alike in other ways, we think that they can differ with respect to their beliefs in virtue of differences in the information stored in memory, even when that information is not being occurrently accessed. In contrast, we do not take an agent's mental states to depend on what she has recorded in an 'external' source of information like a diary. We naively take it that two otherwise similar agents who differ with respect to what they have written in their diaries might differ with respect to what they are disposed to believe if they go on they read what they have written, but they do not on that account differ with respect to what they currently do believe. This is why we think that when a diary-user does go on to believe what she reads in her diary, she forms a new belief that is explained by the new reasons she has available when she forms it. The rational explanation account thus explains the epistemic difference between memory and a diary by appealing to an upstream difference in the metaphysics of mind.

As we have just seen, in our naive belief ascriptions we distinguish implicitly between internal cognitive faculties like ordinary memory and external sources like a diary. Although I am sympathetic to these naive ascriptions, in the remaining sections I will consider the epistemic implications of revisionary metaphysical views that reject the naive ascriptions either by extending the mind to include an apparently external diary, or by contracting the mind to exclude the apparently internal faculty of memory. In Section 7, we will consider the latter kind of revisionary view, which seeks to take our naive attributions of beliefs and their bases in cases of diary-reading and extend them to cases of memory. There I will argue that if we take Connection seriously, then we should take the diary model of the

\footnotetext{
34 See Wedgwood 2002 for an attempt to argue in a different way from considerations involving rational explanation to a kind of internalism about justification.

35 See also Malmgren (2006, 225-226), who notes that one would be disposed to cite facts about what one's sources have said if asked why one holds a belief from testimony. Malmgren admits that this observation about what we are disposed to cite as our reasons do not definitively establish what our reasons are. But they are at least suggestive that one's (psychological) basis for beliefs derived from testimony includes propositions about what one's sources have said.
} 
epistemology of memory to be committed to this revisionary metaphysics of mind. But before turning to these matters I wish to first consider a recent trend that is revisionist in the opposite direction, by seeking to extend to at least special cases of diary-reading the belief attributions that we naively favor in ordinary cases of memory.

\section{The extended mind}

In cases like Two Entries and Sequel, an agent reads a small number of entries in a long-lost diary. Regarding these cases it should be uncontroversial that the diary functions merely as a means of conveying testimony from an agent's past self to that agent's present self. But Andy Clark and David Chalmers (1998) have famously argued that in special cases an agent's use of a diary can become so habitual and systematic that it takes on a functional role in the agent's overall cognition that is very similar to the role usually filled by ordinary biological memory. And in these cases, Clark and Chalmers claim, our ascriptions of person-level mental states to the agent should be no different from our naive ascriptions in cases where ordinary biological memory plays a similar role. Consider an adapted version of Clark and Chalmers' principal example:

Otto's Diary: Otto suffers from chronic memory loss, and he compensates by making heavy use of a diary. On Monday Otto learned from a trusted source that the MoMA is on 53rd St, and he recorded in his diary both the location of the MoMA and the identity of his source. By Tuesday Otto has forgotten both the location of the MoMA and the identity of his source, although he could look up the information in his diary at any time. On Wednesday he will be in midtown Manhattan looking for the MoMA, and he will look up that it is on 53rd St. without bothering to look up the identity of his source.

There is a 'sub-personal' level of explanation on which it is clear enough what is going on both in Otto's head and on the pages of his diary. What is controversial is what it means for Otto's 'person-level' mental states, including Otto's beliefs. Clark and Chalmers have famously advocated the revisionist position that despite what we naively would say, we should say that on Tuesday Otto believes that the MoMA is on 53rd St. , even though this information is stored only in his diary and not in ordinary biological memory. The central thrust of their argument appeals to a kind of functionalism about mental states like belief, along with an auxiliary premise that "the information in the notebook functions just like the information constituting an ordinary non-occurrent belief." Although I am sympathetic to Clark and Chalmers' functionalism, I am skeptical of their conclusion because I am skeptical of the auxiliary premise. But here I want to bracket the question of whether the extended mind thesis is true to focus instead on the epistemic implications it would bring with it.

If we accept the extended mind theorist's revisionist claims about Otto's beliefs, then it is appealing to extend the revisionism to Otto's reasons for his beliefs as well. For if we follow the extended mind theorist in saying that on Tuesday Otto believes that the MoMA is on 53rd St, then presumably we should also say that his reason can be the fact that his trusted source says so, rather than the fact that it says so in his own diary. For surely on Tuesday Otto does not believe that it was on 53rd St. for the reason that it says so in his diary, since on Tuesday he has not yet looked in his diary to see what it says. Nor is it plausible that on Tuesday Otto believes that the MoMA is on 53rd St. but does so for no reason at all. So it appears that the diary theorist must extend his theory in an independently plausible way by saying that Otto's diary serves to maintain not only the state of belief but 
also the reasons the belief is based on. And unless the extended mind theorist wants to claim that Otto changes his reasons for holding the belief when he looks in his diary on Wednesday, he should grant that this is Otto's reason for the belief on Wednesday as well. The upshot is simply that if we buy in to extended beliefs, then we also should buy in to a correspondingly extended conception of the basing relation.

We have observed that even though there is agreement about what is happening at the sub-personal level, there is room for debate about what this means for Otto's personlevel attitudes like beliefs, and for their person-level explanations in terms of reasons. The proponent of the rational explanation account has no distinctive commitments in this debate. Where the rational explanation theorist does have a distinctive commitment is the question of the epistemic implications of the debate over extended mental states. For the rational explanation theorist must say that if we follow the extended mind theorist in adopting an extended metaphysics of mind, then we should adopt an extended epistemology as well. This is because the rational explanation account says that what distinguishes memory from a diary epistemically is the role that each serves in the determination of what your reasons are for your beliefs. If there are special cases where a diary plays a role in the determination of your reasons for belief comparable to that ordinarily played by memory, then the epistemology of such cases should follow the metaphysics of mind. The rational explanation theorist thus should accept the conditional that if Otto's mind is extended, then Otto's situation epistemically resembles ordinary cases of memory rather than cases of testimony from one's former self. In doing so, the rational explanation theorist takes the epistemology of controversial cases like Otto's Diary to go along with the metaphysics of mind.

\section{The contracted mind}

We have just discussed recent theorists who advance a revisionary metaphysics that extends the mind beyond the boundaries we implicitly take it to have in our naive attitude ascriptions. I now wish to consider an older and historically more influential tendency to contract the mind from what we ordinarily take its boundaries to be. A paradigmatic example of this tendency is found in Descartes. Concerning the philosophy of mind, Descartes is most famous for his dualism, under which the mind is an immaterial substance that interacts with the material brain. A less famous but no less distinctive feature of Descartes's philosophy of mind is the surprisingly restricted role that the mind plays in what might broadly be called our 'cognition'. For instance, in the case of memory Descartes held that all but a special, purely intellectual class of one's memories are stored outside the mind in the folds of one's brain.

Descartes surely held this external storage picture for memories of past sensory perceptions, for he thought sensory memories were stored for later retrieval by folds which appeared in one's brain when one perceives an object through the senses. When one tries to remember what one perceived on some earlier occasion, the mind causes the pineal gland to direct some animal spirits through these folds, which in turn causes the pineal gland to wiggle, causing a memory perception to appear in one's mind. It is furthermore plausible that Descartes thought this process of external storage and retrieval also occurred when one recalled earlier demonstrative reasoning which employed one's quasi-sensory faculty of the imagination-for example, when one recalls one's earlier demonstration of a geometrical theorem. While I discuss the historical issue in greater detail elsewhere (Barnett, MS), the upshot is that on Descartes's view much of our cognition involves processes which are 
strictly speaking external to our minds - not only in perception and sensory memory, but also in reasoning involving complex geometrical demonstrations.

More recent diary theorists like Pollock reject Cartesian dualism. ${ }^{36}$ But even Pollock often characterizes person-level mental phenomena in a way that seems to presuppose a restricted conception of genuinely mental states like the state of believing something for a given set of reasons. Pollock says that one's current reasons for believing that $\mathrm{p}$ can include only the contents of one's occurrent mental states, such as one's other occurrent beliefs, or thoughts. When you arrive at the occurrent thought that $\mathrm{p}$ after going through a long and complex argument, Pollock says that your reasons for thinking $\mathrm{p}$ will not include the contents of your non-occurrent beliefs in the argument's initial premises. Instead, your reasons are limited to the content of your occurrent thoughts, which will include only some intermediate lemmas from which $\mathrm{p}$ follows more directly. And since your reasons at this point for occurrently believing the lemmas can include only your occurrent mental states, the only plausible candidates for your reasons for these thoughts are facts about what you currently seem to remember. ${ }^{37}$ The quick and dirty version of Pollock's rationale is as follows:

At any given time we are apt to have many beliefs but few thoughts. It is difficult to hold many thoughts in mind at one time. In particular, we rarely hold an entire argument (even a simple one) in mind at one time. Psychological evidence indicates that people can hold about seven items in mind at one time. $(1999,45)$

We do not hold an entire argument in mind at one time. Rather, we step through it sequentially, holding no more than a few lines at a time in occurrent thought. $(1999,49)$

If we accepted a metaphysical picture like Descartes's, there would be a clear reason to take 'holding an argument in mind' and holding that argument 'in occurrent thought' to be equivalent. The state of having an argument written in a diary in one's pocket is not a mental state, nor (assuming Descartes's view) is having some neural tissue folded in such a way that one is disposed to have an occurrent recollection of that argument. So there is an obvious sense in which neither state is sufficient for holding that argument in one's mind. But unless we give up the commonsensical view that non-occurrent beliefs are mental states, we should grant that if you non-occurrently believe every step of an argument, then you do 'hold the argument in mind'.

\footnotetext{
36 Chisholm notably accepted both the diary model of the epistemology of memory (1989) and an overtly Cartesian picture of the metaphysics of mind (1991) — although Chisholm, unlike Descartes, thought that the mind has a spatial location (somewhere inside the head!). Although it seems to me unlikely to be a coincidence that Chisholm accepted both the epistemology and the metaphysics of Descartes's theory of memory, I am aware of no place where Chisholm makes the connection explicit.

37 As noted in fn. 25 above, there is room for an alternative version of the diary model that says that it is your apparent memories themselves, rather than your awareness of facts about them, that justifies your current beliefs. It is unclear to me whether this alternative version is a better reconstruction of Pollock's view. Still, we can set this interpretive matter to one side, since the differences between these two versions of the diary model will not affect our argument.
} 
Diary theorists like Pollock can be understood as 'externalizing' one's own memory faculties in the following way: On their view, there is a sharp explanatory divide between thoughts and non-occurrent beliefs, for only the former can figure in a rational explanation for one's present belief that $\mathrm{p}$. The premises stored in one's memory, on their view, cannot be among the reasons that justify one's present thought that $\mathrm{p}$, any more than the premises written in a diary in one's pocket can be. But if premises that one non-occurrently believes cannot be among the reasons for one's present thought that $\mathrm{p}$, non-occurrent beliefs seem to be beliefs only in a loose and approximate manner of speaking. For the state of having propositions stored in memory, like the state of having them written in a diary in one's pocket, are treated by the diary theorist as merely grounding a disposition to be in some further occurrent state of occurrently thinking the proposition, which alone can supply the reasons for further thoughts and actions. So on a view like Pollock's, it is the occurrent state of having a thought, rather than any non-occurrent state, which serves the epistemically significant explanatory role ordinarily taken to be characteristic of beliefs.

A diary theorist like Pollock thus wants to say the same thing about the storage and retrieval of information in memory that we naively want to say about recording and later reading a diary entry. That is, he wants to say that in storing and later retrieving a conclusion from memory, your reasons for believing the conclusion change. If you start out believing a conclusion based on a set of premises, then when you later recall the conclusion without recalling the premises, your situation is akin to the detective who reads in his long-lost diary that it was Plum who committed the murder without reading the clues that initially persuaded him of the conclusion. Just as the detective at the later time believes that it was Plum on the basis of its saying so in his diary rather than on the basis of his initial clues, when you recall a conclusion from memory without recalling your evidence, your judgment that the conclusion is true is based on your seeming to remember that it is true rather than on the basis of your initial evidence or premises.

In addition to its unattractive downstream epistemic consequences, a diary-like metaphysics of mind is independently unappealing. Ordinarily we do not take your current reasons for believing a proposition to be limited to things you are currently thinking about. For example, you easily can think of a philosophical view which you have held for some time, for reasons which you have considered persuasive all along. During most of the time you held the view you were not even thinking about it, so your reason for holding the view could not have been a recollection (or apparent memory) that the view is true. When someone asks what you think about the view, you do not typically delay your response until you have had the time to think through your reasons from scratch-you just tell them what you think. But that does not mean that you at that moment only hold the view because you occurrently seem to remember that it is true. Your reasons for holding your philosophical views might change over time in response to objections, but they do not change dramatically from one moment to the next, depending on what you are thinking about.

\section{Conclusion}

There is room in discussions of the epistemology of memory for disagreement about when the fact that you seem to remember that $\mathrm{p}$ amounts to a sufficiently good reason for you to believe that $\mathrm{p}$ is true. But as we have seen, the disagreement between preservativists and diary theorists is not in the first instance a disagreement of this kind, for the preservativist denies in the first place that, in ordinary cases, the fact that you seem to remember that $\mathrm{p}$ is your reason for believing that $\mathrm{p}$ is true. Instead, the question over which 
preservativists and diary theorists divide concerns what your reasons ordinarily are for your beliefs. We have seen another example of this type of disagreement in the debate over alleged examples of extended mental states like in Otto's Diary. As we have said, there appears to be a sub-personal level of explanation on which it is clear what is going on in Otto's head and in his interaction with the diary. What is controversial is what it means at the personal level of Otto's beliefs and reasons. If we accept that there is a tight connection between justification and rational explanation, then disagreements between diary theorists and preservativists about memory can be understood in a corresponding way. The preservativist surely should grant to diary theorists like Pollock that reasoning often involves the storage and later retrieval of information in long-term memory. What they should dispute is the diary theorist's assumptions about how these sub-personal psychological process contribute to the attitudes and reasons of the whole person. If this is right, then the disagreement concerning the epistemology of memory is downstream from a prior disagreement in the philosophy of mind.

More generally, we might divide an overall theory of justified belief into two parts, the first of which concerns distinctively normative matters pertaining to epistemology, while the second of which concerns descriptive matters pertaining to the philosophy of mind. The normative part talks about what would or would not be a good reason for believing that $\mathrm{p}$ - it says things like ' $\mathrm{e}_{1}$ is a strong reason to believe that $\mathrm{p}$, but $\mathrm{e}_{2}$ is not'. The descriptive part talks about the nature of belief and of rational explanation-it says things like 'In this sort of case, you believe $\mathrm{p}$ for the reason that $\mathrm{e}_{1}$, but in that sort of case, you believe that $\mathrm{p}$ for the reason that $\mathrm{e}_{2}$. We want these two parts of our theory to line up with one another in the following way. In a case where we think that an agent's belief is justified, we want the descriptive part to tell us that her reasons are ones that the normative part says are good reasons. And in a case where we think that an agent's belief is unjustified, we want the descriptive part to tell us that her reasons are ones that the normative part says are bad reasons.

I have claimed that in an important sense the epistemology of memory depends upon prior (or 'upstream') questions in the philosophy of mind. But the kind of priority being granted to the philosophy of mind is metaphysical, not methodological priority. Whether you are justified in holding a belief depends metaphysically on what your reasons are for holding that belief. But that does not mean that we must grant methodological priority to descriptive questions of what your reasons are, rather than to normative questions of whether you are justified. In trying to get the moving parts of our overall theory to align, and yield the verdicts about cases that we think they should, we can make adjustments to both the normative and the descriptive components. Regarding ordinary cases of memory like Two Beliefs, we have not had to make any major tradeoffs. For in these cases, considerations in epistemology favor a normative theory that, in conjunction with a descriptive theory that is independently motivated by considerations in the philosophy of mind, yield the verdicts that we want our overall theory of rational belief to yield. But it is possible that for more difficult cases involving forgotten evidence, memory slips, and defeating evidence about one's memory, we will find ourselves forced to make tough choices. If so, we should be as open to making revisionary moves in our philosophy of mind as in our epistemology. 


\section{References}

Adler, Jonathan. 2014. "Epistemological Problems of Testimony." In The Stanford Encyclopedia of Philosophy, ed. Edward N. Zalta. plato.stanford.edu/archives/spr2014/entries/ testimony-episprob/.

Alston, William. 2005. Beyond "Justification". Ithaca: Cornell University Press.

Avnur, Yuval. 2012. “Closure Reconsidered.” Philosophers' Imprint 12(9).

Barnett, David James. 2014. "What's the Matter with Epistemic Circularity?” Philosophical Studies 171(2): 177-205.

—. MS. "Cartesian Skepticism and Cartesian Dualism.” www.davidjamesbar.net.

Bergmann, Michael. 2005. "Defeaters and Higher-Level Requirements." Philosophical Quarterly 55(220): 419-436.

Boghossian, Paul. 2008. “Epistemic Rules.” Journal of Philosophy 105(9): 472-500.

Broome, John. 1999. “Normative Requirements.” Ratio 12: 398-419.

—. 2005. "Does Rationality Give Us Reasons?” Philosophical Issues 15: 321-337.

Burge, Tyler. 1993. “Content Preservation.” Philosophical Review 102(4): 457-488.

- 1997. "Interlocution, Perception, and Memory." Philosophical Studies 86: 21-47.

Clark, Andy and Chalmers, David. 1998. “The Extended Mind” Analysis 58(1): 7-19.

Chisholm, Roderick. 1989. Theory of Knowledge, 3rd Ed. Englewood Cliffs, N.J.: Prentice-Hall. . 1991. 'On the Simplicity of the Soul' Philosophical Perspectives 5: 167-181.

Christensen, David. 2010. "Higher-Order Evidence." Philosophy and Phenomenological Research 81(1): 185-215.

Chrsitensen, David and Kornblith, Hilary. 1997. "Testimony, Memory, and the Limits of the a Priori." Philosophical Studies 86(1): 1-20.

Coady, C. A. J. 1992. Testimony: A Philosophical Study. Oxford University Press.

Conee, Earl and Feldman, Richard. 2004. "Internalism Defended.” In Evidentialism, Richard Feldman and Early Conee. Oxford University Press.

Dogramaci, Sinan. MS. "Forgive and Forget."

Edwards, Jim. 2000. "Burge on Testimony and Memory.” Analysis 60(1): 124-131.

Feldman, Richard. 2004. “Having Evidence.” In Evidentialism, Richard Feldman and Earl Conee. Oxford University Press. . 2005. "Justification Is Internal." In Contemporary Debates in Epistemology, ed. Matthias Steup and Ernest Sosa. Blackwell. 
Gibbons, John. 2006. “Access Externalism.” Mind 115(457): 19-49.

Goldman, Alvin. 1986. Epistemology and Cognition. Harvard.

—. 1999. "Internalism Exposed” Journal of Philosophy 96(6): 271-293.

Greco, John. 2005. “Justification Is not Internal.” In Contemporary Debates in Epistemology, ed. Matthias Steup and Ernest Sosa. Blackwell.

Harman, Gilbert. 1965. "The Inference to the Best Explanation” Philosophical Review 74: 8895.

1973. Thought. Princeton University Press.

Huemer, Michael. 2006. "Phenomenal Conservatism and the Internalist Intuition." American Philosophical Quarterly, 43(2): 147-158.

Hume, David (1993 [1777]) An Enquiry Concerning Human Understanding, 2nd ed., ed. Eric Steinberg. Indianapolis: Hackett Publishing Company, Inc..

Jackson, Alexander. 2011. “Appearance, Reality, and Justified Belief.” Philosophy and Phenomenological Research 83(3): 564-593.

Kolodny, Niko. 2005. "Why be Rational?” Mind 114: 509-563.

Lackey, Jennifer. 2008. Learning From Words. Oxford University Press.

Lipton, Peter. 1998. "The Epistemology of Testimony." Studies in the History and Philosophy of Science 29: 1-31.

- 2007. "Alien Abduction: Inference to the Best Explanation and the Management of Testimony." Episteme 4: 238-251.

Malmgren, Anna-Sara. 2006. "Is There A Priori Knowledge By Testimony?” Philosophical Review 115(2): 199-241.

— forthcoming. "A Priori Testimony Revisited.” In The A Priori in Philosophy, ed. Albert Casullo and Joshua Thurow. Oxford.

McConnell, Terrance. 2010. "Moral Dilemmas." In The Stanford Encyclopedia of Philosophy, ed. Edward N. Zalta. plato.stanford.edu/archives/sum2010/entries/moral-dilemmas/.

Owens, David. 2000. Reason without Freedom: The Problem of Epistemic Normativity. Routledge.

Plantinga, Alvin. 1993. Warrant and Proper Function. Oxford University Press.

- 1988. "Positive Epistemic Status and Proper Function" In Philosophical Perspectives. Vol. 2, Epistemology, ed. James E. Tomberlin, 1-50.

Pollock, John and Joseph Cruz. 1999. Contemporary Theories of Knowledge, 2nd ed. Rowman \& Littlefield.

Pryor, James. 2000. "The Skeptic and the Dogmatist.” Noûs 34(4): 517-549. 
- 2001. "Highlights of Recent Epistemology." British Journal for the Philosophy of Science 52(1): 95-124.

Schiffer, Stephen. 2003. The Things We Mean. Oxford University Press.

Schmitt, Frederick F. 2006. "Testimonial Justification and Transindividual Reasons." In Testimony, ed. Jennifer Lackey and Ernest Sosa, Oxford University Press.

Schoenfield, Miriam. 2014. "Permission to Believe: Why Permissivism Is True and What It Tells Us About Irrelevant Influences on Belief." Noûs 48(2): 193-218.

Turri, John. 2009. “The Ontology of Epistemic Reasons.” Noûs 43(3): 490-512.

. 2011. "Believing For a Reason.” Erkenntnis 74(3): 383-397.

Wedgwood, Ralph. 2002. "Internalism Explained." Philosophy and Phenomenological Research 65(2): 349-369.

—. 2006. "The Normative Force of Reasoning." Noûs 40(4): 660-686.

White, Roger. 2005. “Epistemic Permissiveness.” Philosophical Perspectives 19(1): 445-459. 